\title{
Estado y políticas sociales en el post-neoliberalismo. Un campo de discursividades en tensión*
}

\author{
Lucía Corsiglia Mura*
}

\section{Resumen}

En esta nota intentaremos reponer algunas dimensiones en juego en las transformaciones vigentes en torno a los paradigmas de políticas sociales. Creemos que se viene dando en este campo- y en algunas políticas en especial- una reorientación discursiva, que pretende alejarse de la noción de riesgo como eje rector de la intervención social, hacia un paradigma más centrado en un enfoque de derechos.

Esta transformación la ubicaremos en el contexto de una rediscusión respecto de los modos de concebir al Estado, sus tareas e injerencias, que viene siendo elemento central de las disputas por la reformulación de hegemonías a posteriori de las crisis políticas que barrieron el continente americano, y a nuestro país en particular, a fines de siglo pasado y principios de este.

\section{Palabras clave}

Política Social - Estado - Discurso.

\footnotetext{
* Artículo recibido el 15 de junio de 2013. Aceptado el 13 de agosto de 2013.

* Licenciada en Sociología. Doctoranda en Ciencias Sociales Fahce-UNLP.

Contacto: Iuciacorsiglia@yahoo.com.ar
} 


\section{Abstract}

In this article we will refer some dimensions at stake in the current transformations around social policy paradigms. We believe that has occurred in this field, and in some policies in particular discursive reorientation, which aims to move away from the notion of risk as the linchpin of social intervention towards a paradigm focused on a rights approach.

This transformation, we will place in the context of a renewed discussion concerning ways of conceiving the state, its tasks and interference, which has been central to the disputes over the subsequent reformulation of hegemony of political crisis that swept the Americas, and our country in particular, towards the end of last century and early this.

\section{Keywords}

Social Policy - State - Speech.

\section{Introducción}

En esta nota intentaremos reponer algunas dimensiones en juego en las transformaciones vigentes en torno a los paradigmas de políticas sociales. Creemos que se viene dando en este campo -y en algunas políticas en especial- una reorientación discursiva, que pretende alejarse de la noción de riesgo como eje rector de la intervención social, hacia un paradigma más centrado en un enfoque de derechos.

Esta transformación la ubicaremos en el contexto de una rediscusión respecto de los modos de concebir al Estado, sus tareas e injerencias, que viene siendo elemento central de las disputas por la reformulación de hegemonías a posteriori de las crisis políticas que barrieron el continente americano, y a nuestro país en particular, a fines de siglo pasado y principios de este.

Adelantando los ejes de nuestra hipótesis de lectura, diremos que partimos de suponer que las transformaciones en los elementos políticos articuladores que fundamentan otras concepciones de intervención en política social son parte complementaria de un proceso de impugnación política generalizada de ciertas matrices ordenadoras del ideario neoliberal que dominó los discursos teóricos y políticos de las décadas anteriores. Sin embargo, las redefiniciones semánticas producto de esta disputa aparecerán atravesadas por ambigüedades, continuidades y diferenciales interpretaciones posibles acerca de la implementación de un modelo de políticas sociales que se distancie efectivamente de la focalización neoliberal como 
criterio mayoritario de intervención. Esto no opaca, de todos modos, la potencialidad de lo político en la que se inscriben algunas novedosas experiencias y sus discursividades.

\section{Acerca de las transformaciones en las concepciones del Estado. El retorno del Estado como articulador de nuevos discursos hegemónicos}

Existe una serie de autores que, desde hace un tiempo, vienen observando y haciendo notar la redefinción de las miradas (políticas y académicas) respecto del rol del Estado. Provenimos de décadas de consolidación de discursos negativos respecto del Estado que sostuvieron en el apogeo del imperio del paradigma neoliberal su deseable minimización. A partir de las convulsionadas crisis políticas, sociales y económicas de fines del siglo XX y de una renovada activación del campo de lo político, aparecen en revisión los elementos articuladores de discursos hegemónicos y en ese plano, y especialmente, las cuestiones acerca del Estado y sus representaciones sobre las tareas, roles e incumbencias que le competen. Enmarcadas en un retroceso del paradigma neoliberal, en tanto ordenador político y simbólico dominante, aparecen invocadas en discursividades impugnadoras de aquel ideario valoraciones rejerarquizadas sobre el Estado, miradas que le otorgan lugares de primacía y que le demandan un viraje hacia roles activos y compensatorios, depositando en él renovadas expectativas. Estos elementos circularán en la construcción de nuevos discursos públicos, y serán parte, cada vez con más fuerza, de las demandas activas de sectores sociales y políticos movilizados, que no solo tendrán al Estado como destinatario preferencial de sus peticiones, sino que además aportarán una permanente mirada crítica respecto de su retroceso de las arenas de protección. A su vez, estas miradas rejerarquizadoras acerca del Estado serán insumo de los relatos que empiecen a esgrimirse desde los mismos lugares de gobierno en pos de legitimación de su propio accionar político. Y esto configurará, como veremos en las líneas que siguen, un verdadero elemento de discontinuidad respecto de los anteriores discursos gubernamentales de la región y de nuestro país en particular.

Si recorremos la bibliografía que se encarga de pensar estos nuevos procesos políticos de la región, especialmente para los casos de Bolivia, Ecuador y Venezuela, encontramos sintonía en el peso otorgado al Estado, apareciendo como instancia interpelada, invocada, "prometida"1 de las nuevas construcciones hegemónicas postneoliberales ${ }^{2}$. Autores como Boaventura de Souza Santos (2010) hablan de la

\footnotetext{
${ }^{1}$ Haciendo eje en la teoría política posfundacional para pensar los procesos de hegemonía, se destaca el lugar de importancia que tienen la "'promesa"" como elemento articulador en un entramado discursivo de pretensión hegemónica.

${ }^{2}$ Partimos aquí de la premisa de la dificultad de una definición positiva de post-neoliberalismo. El mero hecho de nominarlo ""post" señala más lo que está dejando de ser que lo que efectivamente haya
} 
Refundación del Estado. Otros, como L. Tapia (2010), A. García Linera (2010) ${ }^{3}$ o P. Stefanoni (2011) también destacan las transformaciones de las formas arquetípicas del Estado moderno para contrastarlas a la luz de los procesos actuales de "reconstrucción" de Estados que atraviesan una suerte de ruptura del Estado-colonial o del Estadoaparente, hacia un proceso político signado por lo que ellos señalan como un "Estado en transición".

Para el caso puntual argentino, también encontramos, aunque con menos radicalidad en cuanto a la observación de las transformaciones sustantivas, similar sintonía en la referencia bibliográfica de una re-emergencia del Estado. Thwaites Rey $(2010,2012)$ será una de las autoras locales que tempranamente va a señalar en varias de sus obras esta reactualización de las temáticas del Estado en las agendas latinoamericanas y en la Argentina en particular. Según ella, "en los albores del nuevo siglo en América Latina se inició un ciclo en el que el papel estatal empezó a adquirir una renovada entidad tanto en el plano valorativo-ideológico como en las prácticas concretas" (2012: 7).

Villanueva (2008), por su parte, contextualiza un punto de inflexión en la crisis de 2001 para pensar el Estado en nuestro país. Para él, en medio de la debacle de diciembre de 2001, y más allá de la profunda crisis económica y de representación, "el único actor que parecía sostenerse era el Estado", agregando que "en los hechos fue su presencia y su intervención la que facilitó una transición hacia cierta normalización política, social y económica" (Villanueva, 2008: 669). De allí en adelante, sostendrá -y especialmente después del recambio presidencial de 2003-, ciertos atributos del Estado habrían entrado en proceso de recuperación, revalorización y consolidación. Grassi (2012: 7) ubica en el mismo discurso de asunción de N. Kirchner, el 25 de mayo de 2003, el inicio de un trastocamiento en el ordenamiento previo de los roles asignados al mercado y al Estado, poniendo súbitamente en tensión, y desde la voz de gobierno, el discurso monolítico acerca de la preeminencia del primero. Ahora, el Estado aparecería invocado para "poner igualdad alli donde el mercado había excluido y abandonado"4. El lugar del Estado pretendiendo abarcar la conducción y resolución de

devenido. En todo caso, estaríamos pensando en el post-neoliberalismo como una etapa en la que se entreteje una nueva configuración de las relaciones de poder entre las clases sociales, con la conformación de bloques sociales dirigentes de tipo sui generis que habilitan condiciones que podrían ser más favorables a las fuerzas populares. Por tomar una definición posible, incorporamos la cita de Thwaites Rey (2010: 30) que utiliza esta categoría para definir a "'gobiernos que, en conjunto y al margen de sus notables matices, pueden llamarse 'pos-neoliberales' y que expresan correlaciones de fuerza sociales más favorables al acotamiento del poder del capital global. En todos estos casos comienza a cuestionarse la 'bondad del mercado' como único asignador de recursos y se recuperan resortes estatales para la construcción política sustantiva. Se conjuga así una retórica crítica frente a las políticas neoliberales, el diseño de propuestas para transformar los sistemas políticos en democracias participativas y directas y una mayor presencia estatal en sectores estratégicos"'".

${ }^{3}$ No puedo dejar de mencionar el doble lugar de actor y autor de García Linera.

${ }^{4}$ Dicho en el discurso de Asunción a la Presidencia por el presidente N. Kirchner el 25 de Mayo de 2003. 
la conflictividad que desbordaba la crisis de 2001 también es señalado por Cortés (2009), quien encuentra en este hecho un elemento explicativo clave del gran apoyo que recibe el gobierno kirchnerista a partir de 2003. El mismo autor alienta también la idea de que en la región sobrevuela un aire de refundación para pensar los actuales procesos de transformación de los estados en Latinoamérica, ya sea en los casos en los que se experimentan reformas constitucionales, o en aquellos en los que la marca está dada por sustantivos cambios de orientación política (Cortes, 2012). También Vilas (2007) habla de un retorno al Estado en el marco de revalorizadas visiones sobre su papel en la economía y en las relaciones sociales; repensándoselo actualmente, y en contraste con las nociones neoliberales, como herramienta virtuosa de desarrollo y bienestar social. Por su parte, Muñoz y Retamozo (2008) aportan importantes pistas para visualizar el importante rol que desempeña la invocación del Estado, junto con la noción de pueblo, en la articulación de un discurso kirchnerista con pretensión de sutura hegemónica.

Esta muy somera referencia bibliográfica da cuenta en principio de una modificación vigente en los modos de concebir al Estado y la productividad que estas nuevas discursividades ${ }^{5}$ tienen en el orden de lo político. Es en este contexto en el cual creemos que cobra dimensión la pregunta por los cambios en las maneras de concebir las políticas sociales, tema en el que nos introduciremos de ahora en adelante.

\section{¿Desde dónde pensar la política social?}

Entrando ya de lleno en el plano de las políticas sociales, lo primero que parece necesario señalar es el lugar nodal que tienen dentro del campo de las intervenciones del Estado. Lejos de cierta idea que asocia las políticas sociales a una suerte de "bombero" del sistema, nos valemos de Belmartino, Levin y Repetto (2001: 53) para situar a las políticas sociales como la actividad del Estado que tiene por finalidad la "producción de condiciones que aseguran la existencia de la sociedad como tal". Esta afirmación nos da cuenta de la relevancia que las discusiones acerca del carácter que estas intervenciones tienen respecto del contexto de reconfiguración de las discursividades sobre el Estado. Siguiendo a los autores recién mencionados, las políticas sociales aparecen como un instrumento irremplazable para la producción y conservación del orden, el bienestar y la integración social. Esquemáticamente podríamos sugerir que el Estado (capitalista), en su necesidad de producción y reproducción de la sociedad, tiene dos funciones clásicas: la acumulación, por un lado, y resolver la legitimidad de la dominación, por el otro. En ese contexto, la política social

\footnotetext{
${ }^{5}$ Por discursividades entendemos más que una simple operatoria de habla o escritura. Sugerimos que un discurso es una suerte de red intersubjetiva de significación, por lo que su articulación implica un momento central en el marco de la constitución de disputas de hegemonía.
} 
entendida en un modo analítico muy general aparece como componente fundamental de estas dos tareas.

Una vía de entrada que ha sido fructífera en nuestro país para el abordaje de la problemática de las políticas sociales, ha sido la propuesta teórica del sociólogo francés Robert Castel (1997), quien marcará una fuerte impronta en la mirada local acerca de la cuestión social y la identificación de los vectores de integración predominantes. En esa sintonía, Andrenacci (2006) dirá que los modos de intervención social "nos invitan a asociar a la política social con los modos con que las sociedades diseñan las formas de pertenencia de los sujetos" entendiendo con esto los "procesos de inscripción de los sujetos en la organización social a través de la cual se obtiene no sólo 'un lugar' físico y simbólico, sino también el derecho a ser sostenido" (Andrenacci, 2006: 46). Integración social, concepto clave para la reflexión en ciencias sociales, queda asociado entonces directamente a la política social, abarcando las órbitas del ingreso y las instituciones, así como la dimensión sociopolítica y cultural. Volviendo sobre Andrenacci y en línea con la referencia a Castel,

Siempre han existido formas a través de las cuales las sociedades 'conjuran el enigma de su cohesión'; dicho más llanamente: formas de intervención de la sociedad sobre sus propios mecanismos de integración (...) Propongo llamar política social a esa intervención de una organización social sobre los modos de funcionamiento de los vectores a través de los cuales individuos y grupos se integran, con grados variables de intensidad y estabilidad a la sociedad. (Andrenacci, 2006: 47)

Así, la política social se constituye para el autor más como un enfoque y campo de problemas que como un conjunto específico de políticas públicas (Soldano y Andrenacci, 2005).

Lo que queda contenido dentro del concepto política social (las áreas de intervención, los sujetos destinatarios, el carácter excepcional o regular de su pertinencia, etc.) son definiciones que varían históricamente y de una sociedad a otra. Existe una taxonomía más o menos consensuada sobre la base del clásico trabajo del sociólogo danés Esping-Andersen (1993) que postula, a modo de tipos ideales, lo que denomina diferentes regímenes de bienestar. En estos, se relacionan con diferente orden de primacía las esferas del mercado de trabajo, de las relaciones de reciprocidad, asociación y sociabilidad cotidianas y la dimensión de acceso a las políticas públicas. Lo social aparece así imbricado en lo político, lo económico y lo doméstico. Sobre este esquema, el autor describe el Estado Liberal, el Estado Corporativo y el Estado Socialdemócrata. Por supuesto, estos modelos funcionan de modo analítico y en las formaciones sociales concretas corporizan realidades más híbridas, atravesadas, a su vez, por las especificidades de cada país. La disputa de intereses dentro de cada proceso histórico concreto, el peso específico de los diversos sectores sociales y la capacidad de imposición de unos sobre otros, así como la construcción de consensos hegemónicos en torno a cómo resolver los procesos de integración social darán cuerpo 
a configuraciones específicas según cada contexto. Especialmente podemos notar esto para el caso de nuestros países latinoamericanos, con niveles variables de desmercantilización de servicios, de desigual cobertura de derechos sociales y estatutos de ciudadanía deficitarios con altos índices generales de exclusión, pobreza y desigualdad.

Como fuera, lo que queda claro es que la definición de los contornos de la política social no es algo que se dé de una vez y para siempre, sino que es producto de diversas tensiones, conflictos y procesos históricos que deben ser leídos en clave de los avatares políticos de cada país. Es en ese sentido que Belmartino, Levin y Repetto (2001) hablarán de un concepto de política social que es "eminentemente histórico" (Belmartino y otros, 2001: 54); y agregamos aquí eminentemente político, en la medida en que es resultado de las disputas que atraviesan el orden social y los consensos construidos respecto de los modos de conseguir su producción/reproducción. No podría ser más gráfica en este sentido la noción de Grassi, quien alude a "la política social (en singular) como la denominación genérica de "la forma política de la cuestión social" (citado en Danani, 2009: 32).

Ahora bien, detallando con un poco más de precisión lo específico de las políticas sociales, Andrenacci (2006) va a sostener un doble patrón de intervención de ellas. Por un lado estarán las intervenciones en el centro, que refuerzan los principales vectores de integración (asociados al trabajo). Este tipo de intervención refiere sobre todo al tutelaje de las condiciones de trabajo y ha redundado en la construcción de la condición asalariada. Por el otro, identificará las intervenciones en los márgenes, sobre los sujetos que no pueden acceder a la integración a través de esos mecanismos principales, es decir, sobre aquellos que no pueden acceder a incorporarse al mercado de trabajo o, cuando lo consiguen, lo hacen de un modo irregular, deficitario. Esta última suele ser una intervención sobre sujetos más que sobre estructuras, asume formas asistenciales y crea formas de integración complementarias, tendiendo a cumplir dos objetivos, "la compensación para aquellos sujetos que no acceden a los mecanismos de integración por razones involuntarias; y la represión para aquellos sujetos que rechazan esos mecanismos (o que no pueden demostrar fehacientemente lo involuntario del no acceso)" (Andrenacci, 2006: 48). Con este criterio, entrarían dentro del campo de la política social todas aquellas

intervenciones públicas que reglan las formas en que la población se reproduce y socializa (sobrevive físicamente y se inserta en el mundo del trabajo y en el espacio socio cultural del estado-nación); y que protegen a la población de situaciones que ponen en riesgo esos procesos. Suelen comprehenderse ahí los grandes universos del empleo, la educación, la salud, los sistemas de seguridad social y la asistencia social (Soldano y Andrenacci, 2005: 32) 
Otra puerta de entrada a la especificidad de las políticas sociales es aquella que hace eje en las intervenciones de regulación de la fuerza de trabajo (criticando del abordaje anterior una suerte de tendencia a ver todo como política social). En esta línea, Danani (2009) va a definir a la política social como "el conjunto de intervenciones sociales del estado, cuya unidad radica en que regulan 'indirectamente' la forma mercancía de la fuerza de trabajo y que lo hacen desenvolviéndose en el terreno de la distribución secundaria del ingreso" (2009: 33). Así, la política laboral será el eje articulador de las intervenciones del Estado, en tanto regula directamente las condiciones de venta y uso de la fuerza de trabajo, participando asimismo de la distribución primaria del ingreso, mientras que lo específico de la política social serán los mecanismos de distribución secundaria del ingreso, refiriendo con esto a procesos de distribución necesariamente mediados por el Estado y que también podrían ser pensados como mecanismos de redistribución. Estas intervenciones sociales están, para la autora, orientadas a producir y moldear las condiciones de vida y de reproducción de la vida. Esta distinción entre el carácter directo e indirecto de intervención, o sobre el momento primario o secundario de la distribución, permite analíticamente ver que, así como siempre hay Estado, también siempre hay políticas sociales (aunque más no sea por omisión de acción). También habilita a concebir a la política social como una creación y no como un mero reflejo o reacción; a la vez que como un proceso en el cual operan conflictos y acuerdos en cuanto a qué es considerado un problema sobre el cual el Estado debe intervenir.

Entonces, a través de lo dicho, queda claro que vamos a pensar a las políticas sociales como algo más que meros dispositivos de control o parches del sistema. $\mathrm{Ni}$ siquiera vamos a pensarlas a través de la célebre expresión de Pierre Bourdieu (1999) que incluye al campo la metáfora de "mano izquierda del Estado". Más bien, vamos a entenderlas como co-constituyentes de las formas de ordenación social, como una de las facetas más visibles del "Estado en acción"(Oszlak y O'Donnell, 1976). Y por tanto, las políticas sociales serán entendidas como resultado contingente de las disputas del orden de lo político en cada momento histórico.

\section{Discursos y modelos en disputa}

Partiendo entonces de que las maneras de concebir las políticas sociales, los "modos" de la política social, varían según los momentos históricos y los acuerdos políticos, vamos ahora a adentrarnos en las actuales transformaciones que se vienen operando en la conceptualización de este campo en cuanto a sus contenidos, modalidades e impactos. En sintonía con las posturas que re-jerarquizan el rol activo del Estado y sobre las que ya hablamos, aparece desde la crisis de 2001, pero más claramente a partir de 2003, un rosario de críticas a las políticas sociales implementadas en el marco del consenso neoliberal. En este contexto, comienza a circular dentro de 
discursos del ámbito académico y político la idea de "nuevos aires en la política social latinoamericana y argentina (...) con cierto interés generalizado por revertir la impronta 'asistenciaista'" (Soldano, 2007: 2). En estos discursos, signados por una suerte de "nuevo clima de época" (Danani y Grassi, 2008), aparecerá incluso la idea de "transición hacia políticas post-focalizadas" (Torres y Del Roble Pensado, citado en Santarsiero, 2012: 167). Se reinstalará en este marco la pregunta por la protección social (Repetto y Dal Masetto, 2011) como modo de repensar conceptual y prácticamente la política social, insertando en las agendas la discusión por el enfoque de derechos (Repetto, 2010) y reinscribiendo los debates entre focalización-universalidad, derechos-riesgo ${ }^{6}$.

Antes de avanzar en estas discursividades actuales tan en tensión con modelos anteriores, resulta necesario hacer una breve caracterización acerca de la historicidad de nuestros patrones de implementación de políticas sociales, cosa fundamental para pensar, asimismo, en los imaginarios interpelados a través de estos relatos en disputa.

Si tuviéramos que ubicar a Argentina en algún cuadrante de los propuestos en la clásica taxonomía de Esping-Andersen, diríamos que lo que caracterizó a nuestro país entre mitad del siglo XX y hasta por lo menos fines de la década del 70 fue el desarrollo de un modelo de Estado Social más bien mixto, en el que primaba una combinación de formas universalistas con corporativas de protección social (Soldano y Andrenacci, 2006). Las primeras, especialmente relacionadas con el sistema de salud y educación; las segundas, asociadas a la adscripción salarial. En un modelo de "ciudadanía estratificada" (Belmartino, Levin y Repetto, 2001), el sujeto de los derechos sociales fue el trabajador formal. Se define, de este modo, un modelo de ciudadanía que no tuvo un carácter universalista, aunque logró articular un vínculo de integración social homogeneizante y ampliamente extendido en el contexto de situaciones prolongadas de pleno empleo. Baste la mención a la amplia significación de conceptos como "justicia social" o "derechos del trabajador", muchas veces aplicada como sinónimo de "pueblo trabajador", articuladores preferenciales del discurso de época.

En este marco, la parte asistencial de la política social, aquella que suplanta los procesos de no integración social por los canales del empleo, quedaba reservada a un lugar marginal (además de a una intervención en los márgenes, parafraseando a Andrenacci).

El imperio de la hegemonía neoliberal, claramente vigente desde el último cuarto de siglo, implicó radicales transformaciones en las formas del Estado en general y en el campo de las políticas sociales en particular. El Estado redefine sus roles, retrayéndose

\footnotetext{
${ }^{6}$ Escapa absolutamente a los alcances de este trabajo adentrarnos en la discusión acerca de la distancia que podría mediar entre dichos y hechos, tensión siempre presente a la hora de pensar en abordajes de discursos. De todas maneras, cuando definimos el tratamiento que daríamos al discurso como un elemento central en el proceso de construcción y disputa de hegemonías, dejamos establecido el carácter performativo que le asignamos a la conformación de una cadena argumental, dándole entonces relevancia más allá de verificarse su efectiva realización.
} 
de algunas tareas que le habían sido prioritarias tanto en el campo de la producción, como de la distribución primaria y secundaria. Asimismo abandona su tradicional rol de tutelaje, dejando en libertad casi total al mercado y asimilando estructurales transformaciones respecto de las condiciones contractuales de trabajo. Podríamos sintetizar este aluvión de cambios estatales en la enumeración de los procesos de privatización, descentralización, focalización, desconcentración, remercantilización y tercerización (Soldano y Andrenacci, 2006; Danani, 2012).

En el plano de las políticas sociales, estas transformaciones tienen un impacto decisivo. Si habíamos dicho que la cara asistencial era marginal en el modelo del Estado Social, para el caso del Estado neoliberal, la ecuación se invierte. La tendencia al abandono de la regulación salarial y la privatización parcial de la seguridad social son acompañadas por una explosión de múltiples políticas asistenciales. Se da una "fuga" hacia formas masivas y sistemáticas de asistencia social. Las reformas de la política social de los años 90 se desplazan de un objetivo como el desarrollo con igualdad centrado en la extensión de protección pública a través del empleo formal y de grandes instituciones universalistas (cuestionado por inalcanzable y costoso en el contexto de la crisis del Estado de Bienestar), a otro cuyo objetivo y limitación esencial radicaba en "el combate a la pobreza"7 y el refuerzo de una red de seguridad mínima por detrás y debajo del mercado de trabajo (Soldano y Andrenacci, 2006: 18).

Se diseñaría así la concepción de un tipo de política social basado en un conjunto de intervenciones cortas y puntuales con formato de "proyectos", diseñadas con formas de focalización extrema y cuyo objetivo se inscribía en amortiguar impactos de la reconversión macroeconómica (concibiendo la dimensión de la vulnerabilidad como efecto no deseado de estas transformaciones en lugar de como consecuencias estructurales). La focalización implicó un nivel de creciente selectividad de la población destinataria, especialmente asociada a la noción de riesgo. Así, la definición de condiciones de vulnerabilidad fue constituyendo en el mismo acto la definición de una población-objeto. Esta población, ubicada en los márgenes del mercado de trabajo, aparecería crecientemente particularizada en grupos y territorios de riesgo, y debería someterse a procedimientos de demostración de sus niveles de precariedad para competir con recursos escasos ante otros potenciales "beneficiarios".

Aparecen entonces múltiples programas de asistencia alimentaria y nutricional, asistencia de salud, de infraestructura, de empleo. Este desarrollo va propiciando una asociación lineal en los discursos cotidianos, mediáticos y en la propia práctica estatal, que identificará "políticas sociales" con programas y políticas asistenciales (Andrenacci, 2002: 60), dando un claro contorno a las transformaciones operadas en lo que se

\footnotetext{
${ }^{7}$ No podemos dejar de destacar la centralidad del concepto de pobreza en el marco conceptual de las políticas neoliberales, donde claramente la definición de la cuestión social se desliza de la problemática de los trabajadores a la problemática de los pobres (Grassi, 2008). Para pensar los efectos políticos de esta redefinición de los sectores populares a través de la noción de pobre, puede verse Merklen (2005).
} 
concebiría dentro del campo. Asimismo la retórica de esta intervención gravitó en torno a una lista de 'atributos', una "taxonomía de pobreza" (Soldano, 2007) que consolidó discursos de identificación de la población potencialmente receptora.

El colapso de 2001 marca un antes y un después para el consenso neoliberal en nuestro país. Como ya dijimos, una serie de discursos impugnadores han emergido con fuerza desde entonces. Y especialmente desde 2003, aparece la invocación a una presencia más activa del Estado, operando como articulador central de un proceso hegemónico que pareciera haber suturado, aunque sea temporalmente, parte de las heridas que generaban disrupciones radicales por aquel entonces.

En este contexto surgen también, y más allá de las múltiples continuidades evidentes, nuevas proposiciones respecto de la política social. Estas formulaciones buscan diferenciarse explícitamente de los parámetros de sus antecesoras. Harán, como ya vimos, un llamamiento a la desfocalización, a criterios de universalidad y, sobre todo, traerán al ruedo una noción de derechos.

En la sección que sigue, recorreremos muy sucintamente algunos de estos postulados actuales que se presentan como un novedoso enfoque de políticas sociales, tratando de dejar presentada una agenda de preguntas e inquietudes al respecto.

\section{Entre derechos y ciudadanías. Potencialidades y supuestos de estas enunciaciones}

El enfoque de derechos aparece como una carta de posicionamiento esgrimida desde distintos ámbitos para sentar posición contra aquello que genéricamente podríamos llamar las políticas sociales neoliberales. Esta concepción aparece reiteradamente invocada en la reformulación de programas diversos dentro del ámbito de las políticas asistenciales, así como en otras iniciativas más novedosas. Ahora bien, ¿de dónde surge y de qué presupuestos epistemológicos se nutre?

La definición teórica del enfoque de derechos se ubica en "un marco conceptual para el proceso de desarrollo humano que está basado normativamente en principios y estándares internacionales de Derechos Humanos y operacionalmente dirigido a respetarlos, protegerlos y satisfacerlos", y proviene del acuerdo internacional de diversas entidades entre las que se encuentran, entre otras, diversos ámbitos de Naciones Unidas (Unicef, Cepal) ${ }^{8}$.

\footnotetext{
8 Si bien las organizaciones de cooperación internacional que están proponiendo este enfoque (Departamento de Desarrollo Internacional del Gobierno del Reino Unido (DFID), el Organismo Sueco de Cooperación para el Desarrollo Internacional (OSDI), el Fondo de las Naciones Unidas para la Infancia (UNICEF), la Organización de las Naciones Unidas para la Educación, la Ciencia y la Cultura (UNESCO), el Fondo de Desarrollo de las Naciones Unidas para la Mujer (UNIFEM) y la Oficina del Alto Comisionado de las Naciones Unidas para los Derechos Humanos (Cepal) no son las más directamente identificadas con los organismos internacionales que promovieron el Consenso de Washington; tampoco han sido del todo ajenas algunas de ellas a la implementación de aquellas políticas, lo que debería ponernos en alerta acerca de las ambigüedades y distintas intencionalidades que pudieran subyacer detrás de esta propuesta.
} 
En líneas generales, este enfoque parte de reconocer que los sujetos son titulares de derechos (civiles, políticos, económicos, sociales y culturales), lo que cambiaría la lógica de los procesos de elaboración de políticas, poniendo como punto de partida la existencia de sujetos con derecho a demandar determinadas prestaciones y conductas que les corresponden, en lugar de personas con necesidades, "beneficiarios" que requieren asistencia (Abramovich, 2006). Incluye como premisa el reconocimiento de la universalidad, indivisibilidad e interdependencia de los derechos, y su adopción es leída en clave de empoderamiento ${ }^{9}$ de los sectores vulnerables o excluidos ${ }^{10}$. Esto significaría que el reconocimiento de sujetos con derecho establecería en el mismo acto obligaciones correlativas al Estado, otorgando, entonces, la capacidad y legitimidad de demanda ante su incumplimiento. Siguiendo a Pautassi (2010: 36)

la relevancia de incorporar el enfoque de derechos al amplio espectro de políticas públicas radica en que reconoce explícitamente la relación directa entre el derecho, el empoderamiento de sus titulares, las obligaciones correlativas y las garantías, todo lo cual conjuga en una potencialidad que puede actuar como una forma de garantizar situaciones que tiendan a la equidad en el marco de situaciones sociales marcadamente desiguales.

En este sentido, se sugerirá que en realidad el enfoque de derechos no dice en sí mismo mucho acerca del contenido específico de las políticas, pero sí puede decir algo sobre su orientación general, a la vez que brinda un marco conceptual para su formulación e implementación. Esta formulación propuesta por Abramovich parece poco ambiciosa, aunque vista a la luz de las condiciones de déficit social de nuestra región, puede cobrar alguna relevancia para aportar a procesos de desnaturalización de condiciones de desigualdad: "las obligaciones que imponen los tratados de derechos humanos no son exorbitantes (...) sino que ponen de relieve las acciones mínimas que el Estado tiene el deber de realizar" (Abramovich, 2006: 38) ${ }^{11}$. Entre estas acciones

\footnotetext{
${ }^{9}$ El concepto empoderamiento, ampliamente asociado al discurso de las agencias internacionales, connota a nuestro criterio no pocas objeciones posibles. En particular, porque plantea la posibilidad de una distribución distinta del poder, pero no sugiere la necesidad de eliminar las condiciones de subalternidad en términos estructurales. Al suponer la posibilidad de un poder compartido, no pretende anular la relación de subordinación, sino morigerarla.

${ }^{10}$ Nótese que este enfoque sigue utilizando algunos términos nodales de las políticas de corte focalizado.

${ }^{11}$ En este sentido, es necesario recordar la impronta que el concepto de derechos humanos tiene en nuestra región. Surgido en el contexto de la trágica experiencia de las dictaduras latinoamericanas, como un decálogo de aquellas conductas que el Estado no debería tener: no torturar, no secuestrar, no desaparecer, no perseguir por razones políticas, no entrometerse en la vida privada y familiar de las personas, no discriminar. En los últimos años, el cuerpo de principios, reglas y estándares que componen el derecho internacional sobre los derechos humanos ha fijado con mayor claridad no solo las obligaciones negativas del Estado, sino también un cúmulo de obligaciones positivas, definiendo no sólo lo que el Estado no debe hacer, sino también aquello que sí debe hacer para lograr la plena materialización de los derechos civiles y políticos y también económicos, sociales y culturales.
} 
mínimas, aparecerá el listado de derecho a la educación, a la salud, al acceso a infraestructura básica, a la vivienda, a la seguridad social, detallando una serie de responsabilidades estatales que demandarían acciones positivas por parte del Estado.

Pautassi (2010) destaca que la perspectiva de derechos incorpora el principio de igualdad, no discriminación ${ }^{12}$ y responsabilidad, abriendo las puertas a la vigente discusión entre focalización-universalidad. Discusión que —no está de más decirlonos reenvía directamente a los imaginarios (con componentes un tanto míticos si somos estrictos en cuanto al concepto de universalidad) del viejo Estado Social de mediados del siglo XX.

Algunos trabajos que comienzan a explorar esta transformación en la construcción discursiva de la política social en nuestro país señalan la búsqueda desde 2003 de formulaciones que interpelan la noción de ciudadanía o igualdad. Siguiendo a Borghini, Bressano y Logiudice (2012:3) "la política social de los últimos años se ha enunciado como una política tendiente a 'restituir derechos' a partir de intervenciones más 'universalizadoras', permanentes y complementarias de la política de promoción de 'empleo genuino'."13

En este sentido, cuando repasamos las investigaciones recientes que comienzan a indagarse por las políticas sociales del período kirchnerista, encontramos una suerte de diferenciación que periodiza la preeminencia de diferentes matrices de intervención. Así, aparece un primer momento, identificado por lo menos hasta 2007, cuando correrán dos ejes fundamentales que serán explicativos de la persistencia de una estructura social fragmentada. Por un lado, se apostará al fortalecimiento de los mecanismos de integración social a través del mercado de trabajo (en franca recomposición desde el inicio de la gestión y por lo menos hasta $2008^{14}$ ) y sus consecuentes impactos en los dispositivos de seguridad social. Por el otro, esto se verá acompañado de la prolongación, a veces con reconversión a nuevos programas reformulados con una retórica más progresista pero con similares supuestos de fondo, de un extendido abanico de políticas de transferencia de ingresos para atención a poblaciones vulnerables con claro corte focalizador. Volviendo sobre la formulación de Andrenacci antes mencionada, una política en el centro, orientada a la inclusión a través del empleo, y una política en los márgenes, (aunque no marginal, si pensamos el alcance de su extensión) para los que quedan fuera de aquellos patrones integrativos.

\footnotetext{
12 No solo incorpora la perspectiva de no discriminación, sino que aparte puede implicar en algunos casos la adopción de acciones afirmativas para garantizar la inclusión de grupos o sectores de la población tradicionalmente discriminados.

${ }^{13}$ Entrecomillado en el original.

${ }^{14}$ Según datos del INDEC la tasa de desocupación descendió de un $22.4 \%$ en 2002 a un 8.4 \% en 2008. En esa fecha, comenzó a registrarse un cierto amesetamiento en la recomposición del mercado de trabajo. Mientras que algunos autores asignaban a esto los efectos de la crisis internacional, otros comenzaban a detectar elementos endógenos del propio modelo posconvertibilidad. Puede verse para más detalle Arceo y otros (2010).
} 
Este primer panorama nos encuadra una imagen en la cual, pese a la magnitud de la mejora de las condiciones sociales motorizada por la recuperación del mercado de trabajo y por una serie de políticas regulatorias activas (recomposición salarial, restablecimiento de los ámbitos de negociación colectiva, dispositivos de combate a la informalidad, etc. ${ }^{15}$ ), se estuvo muy lejos de mitigar una estructura social heredada con altísimos niveles de fragmentación y desigualdad. Etchemendy y Collier (2007) hablarán en este sentido de la consolidación, a través del restablecimiento del dinamismo de la conflictividad sindical, de un neocorporativismo segmentado que no hace sino producir (e incluso profundizar) la diferenciación dentro de las clases trabajadoras entre incluidos y excluidos del sistema formal.

Entonces aparecerá como evidente que, si la apuesta hasta aquí se basaba fundamentalmente en la recuperación del empleo formal como herramienta igualadora, los efectos de recuperación del sistema de protección social no podrían sino ser limitados y escasamente desmercantilizadores, en tanto siguiera articulándose la protección social a través de los (desiguales) segmentos contributivos.

Ahora bien, a partir de 2008 y 2009, en medio de la crisis de alcance global, y hasta cierto punto enmarcados en una serie de medidas anticíclicas poco ortodoxas ${ }^{16}$, emergieron otros ejemplos de políticas públicas que dieron cuerpo a las discusiones acerca de cambios en la matriz de intervención social. Especialmente destacará el quiebre del criterio contributivo como único eje de acceso al sistema de protección social, habilitando la posibilidad del despliegue de argumentaciones de tipo universalista y en clave de derechos. Debemos por supuesto mencionar que estas políticas, propias de una mirada distinta respecto de las nociones de protección, coexistirán hasta la fecha con las anteriores formas de intervención, que mayoritariamente se construyen como continuidad de los paradigmas neoliberales basados en la noción de riesgo.

\section{Reforma Previsional y Asignación Universal por Hijo. ¿Nueva matriz de la política social?}

Las dos iniciativas que hacen mayormente de soporte a este debate respecto de la restitución de la dimensión de derecho como enfoque de la política social son la reforma del Sistema Previsional y la Asignación Universal por Hijo. Desarrollaremos muy sucintamente algunos de los elementos en relación con la disputa de significaciones que venimos reponiendo y que ambas iniciativas disparan.

En el caso de la Política Previsional, y más allá de las medidas referidas a los mecanismos de adecuación de haberes, encontramos una secuencia de

\footnotetext{
${ }^{15}$ Puede verse al respecto Palomino (2010).

${ }^{16}$ Ver Arceo y otros (2010) y Repetto y Dalmasetto (2011).
} 
transformaciones referidas a la expansión del sistema que tiene su inicio en 2004, con la sanción de la Ley de Jubilación Anticipada. Esto será ampliado en 2005 a través de un decreto que habilita la moratoria previsional, permitiendo facilidades de pago de los aportes al tiempo que se habilita el cobro inmediato del haber. Esto consagraría en última instancia al Plan de Inclusión Previsional en los bordes de la política contributiva $^{17}$. La magnitud de la inclusión al sistema previsional que esta medida implicó se grafica con la expresión de Alonso y Di Costa (2011), que hablan para 2007 del "salto discontinuo más significativo en la historia del sistema previsional argentino" sobrepasando holgadamente los niveles históricos en nuestro país de cobertura previsional, además de superar los parámetros de cobertura para toda Latinoamérica ${ }^{18}$. Las medidas fueron profundizadas en 2007 con la Ley de Libre Opción, que para 2008 terminó coronando primero con la Ley de Movilidad y después con la creación del Sistema Integrado Previsional Argentino (SIPA), reestatizando el sistema de previsión y disolviendo el sistema de capitalización individual y privado de las AFJP para volver al sistema de reparto administrado por el Estado.

Más allá del impacto cuantificable recién mencionado muy por arriba, citaremos a Danani y Beccaria (2011), para observar la dimensión político-cultural de esta reforma. Esta reforma de 2008, llamada contra-reforma por las autoras, es planteada, según ellas, en términos refundacionales, insertándose de lleno en la disputa de significados y desbordando el ámbito de lo específico de esta política. La reforma previsional apelaría a un contexto discursivo basado en principios de solidaridad, redistribución e inclusión social. Asimismo, tomará nota de los límites del eje organizador atado al desempeño laboral de los sujetos, reconociendo la cobertura previsional dentro de las obligaciones del Estado al fundamentar el lugar del "nuevo sistema de reparto en la reivindicación del papel 'igualador' de la intervención estatal y la necesidad de proveer certezas y seguridades a las personas" (Danani y Beccaria, 2011). Siguiendo a estas autoras, en el discurso oficial acerca del campo previsional se verifica un pasaje argumental de la definición de beneficios hacia la noción de derechos, ubicando el lugar preeminente que implicó esta reforma en el ámbito de las disputas por la significación del sujeto de

\footnotetext{
${ }^{17}$ Algunos autores, dirán que estas jubilaciones son parte de un esquema "semi-contributivo" (Bertranou (2010), citado en Repetto y Dalmaseto, 2011: 24). A partir del Decreto 1454/2005 de creación del Plan de Inclusión Previsional, se suavizaron los requisitos contributivos, dando acceso a personas que cumplían con la edad jubilatoria pero no con los requisitos contributivos. Esto generó un masivo ingreso al campo protegido de sujetos que estaban por fuera del paraguas de la seguridad social. Se calcula que para 2007 se habían ya registrado alrededor de 2 millones de nuevos jubilados a raíz de la moratoria. Para más detalle puede consultarse Danani y Beccaria (2011). Estas autoras, sin embargo, enfatizarán que más que poner en cuestión el criterio de lo contributivo (transferido a la noción de pago, a través del descuento por moratoria), estas modificaciones han relajado más bien otros criterios, como el requisito de años de trabajo o de edad jubilatoria.

18 Los indicadores de 2007 señalan que los niveles de cobertura previsional superaron el $80 \%$ de las personas mayores de 65 años (Alonso y Di Costa, 2011). En sintonía, Grassi (2012: 22), por su parte, sostiene que las jubilaciones y pensiones del régimen de la seguridad social ascendían para 2010 al $88 \%$ de la población adulta mayor argentina.
} 
la protección social. Estos giros argumentativos respecto del rol del Estado y las nociones de derecho nos meten de lleno en el plano político, en tensión por las atribuciones de sentido, reenviándonos a diferenciales concepciones de ciudadanía. Sobre esto, volveremos en nuestras conclusiones.

Respecto de la Asignación Universal por Hijo ${ }^{19}$, dicen Repetto y Dal Masetto (2011: 26) que "es la principal medida de protección social de las últimas décadas en Argentina". Creada en octubre de 2009 por un DNU ${ }^{20}$, se integra como tercer componente del Régimen de Asignaciones Familiares, para dar cobertura a los hijos en edad escolar de los trabajadores desempleados e informales, así como a los hijos de los receptores de otros planes sociales que paulatinamente fueron traspasados a la AUH. Establece como sujetos de derecho a los niños, niñas y adolescentes o a las personas discapacitadas, que no tengan otra asignación familiar y que pertenezcan a grupos familiares que se encuentren desocupados, se desempeñen en la economía informal, sean monotributistas sociales o trabajadores/as domésticos.

Existe cierta tendencia a establecer como un antecedente inmediato de la AUH al Plan Familias por la Inclusión Social (IDH), creado en 2004 y al cual fueron transferidas las mujeres con hijos menores de 19 años que percibían anteriormente el Plan Jefas y Jefes de Hogar Desocupado (PJJHD). El Programa Plan Familias se basa en la transferencia de ingresos condicionada por contraprestaciones de controles de salud y educación para los hijos, poniendo el acento en el núcleo familiar como articulador de sociabilidad e integración social básica, acrecentando el rol reproductor de la mujer y suponiendo la caracterización como "inempleables" de sus perceptoras. A partir de 2009, el grueso de los núcleos familiares de estas mujeres incorporadas al Plan Familias migraría hacia la AUH a través de la cobertura de la asignación familiar, de la que ahora serían titulares los hijos. Con la $\mathrm{AUH}$, el sujeto de derecho referido pasará a ser el niño, niña o adolescente. Esto pese a que la asignación siga siendo percibida por los progenitores (a partir de 2013, especialmente por las madres), habilitando a que sea vista como una continuidad en términos de estrategias familiares de ingreso, lo que constituye una primera y muy importante diferencia. Otro contraste de relevancia con los anteriores programas asistenciales, y no solo ya con el Plan Familias, será que como se mencionó líneas arriba, la AUH ampliará el Sistema de Seguridad Social, incluyéndose como parte de un derecho ya establecido de los hijos/as de los trabajadores y sosteniendo su financiamiento a través de criterios de solidaridad extendidos a este subcomponente no contributivo. Este elemento no contributivo e

\footnotetext{
${ }^{19} \mathrm{AUH}$ de ahora en adelante.

${ }^{20}$ Si bien la AUH fue creada por un Decreto de Necesidad y Urgencia, no puede si no ser leída en clave de una demanda de larga data de diferentes sectores sociales y políticos que promovían algún tipo de ingreso universal a la niñez. De hecho, para el momento de su creación, ya existían en carpeta una serie de proyectos legislativos que abordaban la temática.
} 
igualador en términos de derechos aporta, al igual que en el caso de lo dicho para el Sistema Previsional, una diferencia radical respecto de la concepción de los sujetos destinatarios de la protección social.

Finalmente, otro elemento que da cuenta de la novedad de esta política lo encontramos siguiendo a Repetto y Dalmaseto (2011: 28), quienes dicen que, si bien los criterios de selección de destinatarios en la AUH no son realmente universales, en la práctica puede observarse una suerte de universalización de hecho por la gran magnitud de su alcance. ${ }^{21}$

Entonces, la AUH se trata de una política de corte netamente no contributivo, que está destinada a cubrir aproximadamente al $40 \%$ de los menores de 18 años de nuestro país y que se encontraban anteriormente por fuera de la cobertura de la seguridad social (Alonso y Di Costa, 2011: 19, 20). Así, complementa una cobertura que se plantea en igualdad de condiciones respecto de los niños, niñas y adolescentes y los hijos/as discapacitados a cargo, equiparando al menos en este punto los derechos de los hijos/as de los trabajadores formales e informales, privilegiando el derecho de los sujetos y la obligación del Estado de protección por sobre la capacidad de aporte del trabajador"22. Para Grassi (2012: 23), la AUH constituye "una cuña en el régimen clásico de la seguridad social" al extender la cobertura a grupos familiares que se desempeñan en la economía informal, a la vez que recupera a la órbita protectoria a sujetos que quedaban siempre encasillados dentro de alguna de las categorías merecedoras de

\footnotetext{
${ }^{21} \mathrm{Y}$ aquí parece pertinente no pasar por alto la no menor diferencia que existe entre los conceptos de universalidad y masividad. Universalidad sugiere la existencia de igualdad de posibilidades para todos los ciudadanos/as para acceder a una política pública. Las políticas universales generan derechos, y universalidad significa que este derecho es "para todos"; mientras que masividad desanda el camino de reconocimiento de derecho y refiere a un alcance limitado a solo "para muchos". Esta diferencia entre "todos" y "muchos", más allá de cuán extendida esté la cantidad de sujetos incluidos en el "muchos", deja a una parte de la población total excluida. Así, habilita a la persistencia de criterios rectores de asignación, elegibilidad, merecimiento, etc. Es altamente interesante el tratamiento que de este aspecto se da en De Sena (2011), autora para la cual, en las formulaciones recientes sobre política social, el término masividad aparece como una forma ocluida de focalización, evidenciando la necesidad de ampliar la cobertura a mayor cantidad de personas, pero sosteniendo dispositivos de intervención de matriz focalizada que aparecerán, en todo caso, en mayor "dosis". De todas maneras, para el caso de la AUH, sostendremos acá que, pese a las salvedades respecto de las condiciones que limitan su plena universalidad, se trata por múltiples razones de una política pública con diferencias relevantes respecto de los programas focalizados (masivos o no) que venían siendo las formas de intervención social dominante.

${ }^{22}$ Respecto de esta igualación de derechos, desde poscionamientos críticos, uno de los elementos que se toman en consideración para marcar continuidades entre la AUH y otros programas de transferencia de ingresos condicionados es la exigencia de controles sanitarios y educativos que esta asignación dispone como requisito de continuidad. A tal respecto, es estrictamente cierto que estas exigencias sostienen una lógica ya instaurada en el Plan Familias y que marcan, prima facie, una diferencia de derechos y obligaciones respecto de los hijos/as de los trabajadores del mercado de trabajo formal que no deben cumplir con la obligación de demostración periódica. En este punto, diremos, matizando un poco la mirada crítica, que en todo caso estas condicionalidades también podrían ser consideradas desde una mirada protectoria, además de sugerir que en última instancia no hacen sino reforzar mecanismos de observancia sobre obligaciones preexistentes que competen a las familias, como la escolaridad y la vacunación de los menores, así como evidencian obligaciones estatales (en general incumplidas en su plenitud), tales como la garantización de infraestructura para el desarrollo de las exigencias requeridas.
} 
programas puntuales y transitorios para poblaciones consideradas vulnerables. La AUH, al extender una matriz de derechos, se diferencia notablemente de la lógica de los planes de transferencia de ingreso basados en el criterio de riesgo, y en su diseño prevé, como ya adelantamos, la absorción de los Planes de Transferencia Condicionada de Ingresos más relevantes hasta la fecha (el PJyJHD y el Programa Familias por la Inclusión Social).

Queda entonces claro, a partir del pequeño recorrido realizado, que el campo de las definiciones acerca de la política social viene siendo escenario de disputa y de transformación, enmarcado en los procesos más abarcativos de reconstrucción de hegemonías que atraviesa a nuestro país, y a través del cual, el Estado se reconstituye como una pieza clave. Las experiencias reseñadas a través de la Reforma Previsional y de la AUH dan cuenta de la corporización concreta, a través de políticas específicas, de nuevas miradas respecto de la protección, dejando en evidencia el espacio abierto de rediscusión de los parámetros de la integración, de la dimensión de roles y responsabilidades estatales y de la concepción de los sujetos destinatarios.

Como ya mencionamos, esto no significa que no persistan, con gran despliegue, otras lógicas de intervención social que sostienen y continúan criterios propios de las políticas focalizadas y asentadas en nociones de vulnerabilidad y riesgo, construyendo verdaderas capas geológicas de programas que se reformulan a sí mismos desde hace décadas. Más bien, sugerimos que esta coexistencia de criterios distintos de concepción de la política social habla justamente de las tensiones del orden de lo político que atraviesan al campo.

\section{Interrogantes y expectativas}

Para dar cierre a este trabajo, enunciaremos algunos interrogantes y advertencias que, más allá del optimismo que vienen despertando estas miradas desde el enfoque de derecho, quedan abiertos a una lectura más global de la política social y de sus tramas discursivas actuales.

En primer lugar, obliga mencionar que la invocación del enfoque de derechos trae consigo una relación inmediata a la noción de ciudadanía, aunque las significaciones del concepto de ciudadanía varían ampliamente según el contexto discursivo en el que se inscriban. Como bien nos recuerda Estela Grassi (2008: 36), la apelación a la ciudadanía no aporta especialmente en sí misma un valor progresivo, ya que "sirvió tanto para justificar la política focalizadora y tercerizadora de las intervenciones sociales, como para su crítica y exigencia de universalidad sostenida por el Estado". Y esto porque el sujeto de los derechos de ciudadanía es el individuo, base y esencia de las nociones liberales. 
Además, recordamos que incluso en el momento de mayor extensión de los derechos sociales en nuestro país, la noción de ciudadanía reenviaba a un tipo de integración social mediada a través del empleo formal. También en esta renovada discusión sobre el campo de la política social y las nociones de bienestar, aparece, como ya vimos, una fuerte carga trabajo-céntrica. La apuesta parece estar principalmente en la recomposición del trabajo-empleo como vía de acceso a bienes y servicios y residualmente la prolongación de dispositivos de planes transitorios de asistencia para quienes no consiguen ese acceso. Esta perspectiva de bienestar asociada al empleo como meta de potencialidad universalizable contrasta con la caracterización de un mercado de trabajo altamente fragmentado donde existen sectores con insuficiente o nula capacidad de integración a sus circuitos formales y de donde deviene la consideración de "inempleabilidad" sobre la que se basan algunos programas asistenciales actualmente vigentes. Esto parece también haber sido asimilado a partir del régimen semicontributivo de la Reforma Previsional, pero mucho más explícitamente a partir de la instauración de la Asignación Universal por Hijo en el año 2009, que significa un reconocimiento cabal de derechos de protección social a aquellos que mantienen una relación de exterioridad del mercado formal de trabajo.

Finalmente, siempre quedan los elementos críticos que, por obvios, no dejan de ser relevantes. Salvando el caso de la AUH recién mencionada, el resto de los programas vigentes, incluso aquellos que tienen una formulación en términos de derechos, tienen cupos o plazos temporales de inscripción. Por su parte, en todos los casos aparecen requisitos que limitan su población-objeto echando por tierra, más allá de reconocerles una gran masividad, la declamada pretensión de universalidad. En este sentido, los límites temporales impuestos recientemente a los planes de moratoria para jubilación ponen coto a la capacidad de pensar en términos universales a la política de inclusión previsional que tanto aportara a la expansión de cobertura social. En el caso de la AUH, el límite de cobertura de hasta cinco hijos/as por grupo familiar implica una frontera absolutamente arbitraria y contraria a una noción de derechos. Del mismo modo, la incompatibilidad con otros programas asistenciales en los que los padres estén inscriptos, así como las limitantes por ingreso de aquellos padres que superan el Salario Mínimo pero aun así tienen empleo no registrado, evidencian la persistencia de rasgos de focalización a la hora de definir la población destinataria. A la vez, se cae de maduro que los montos de los subsidios de los programas de transferencia de ingresos que aún hoy persisten se encuentran muy por debajo de cualquier noción de bienestar, vulnerando toda concepción de derecho.

Así, el avance del enfoque de derechos aparece tensionado dentro de las distintas intervenciones de la política social, planteando, a nuestro criterio, un escenario político altamente interesante. Más allá de las limitaciones recién mencionadas respecto de su puesta en práctica, y aun observando la convivencia con una serie de ambigüedades y claras continuidades de otros patrones contradictorios de intervención social 
asimilables a las matrices hoy desdeñadas, sostendremos que la utilización de la noción de derecho como insumo discursivo de esta reformulación de la gramática del campo de la política social marca puntos de disputa que se mantienen latentes y que podemos ubicar como herencia de los conflictos hegemónicos que atravesaron y aún surcan a nuestro país.

La mención a derechos y ciudadanía no necesariamente implica una potencialidad progresiva. Así, reposicionar el lugar del Estado e instalar la noción de sujetos de derechos bien puede ser una agenda propia de una concepción liberal e individualizante, amparada en muchos casos por organismos internacionales en su búsqueda de calmar aguas ante la experiencia reciente de escenarios altamente disruptivos. Pero seguramente, también puede ser leída en clave de una agenda emergente, nacida de las conflictivas luchas de organizaciones y movimientos sociales que hace apenas unos años dominaban y desbordaban la escena política. Un sujeto de derechos se reconoce de la mano de suponer un Estado con obligaciones. Esta enunciación ha sido resultado del proceso colectivo de desnaturalización de desigualdades, politizando el campo de lo social y dislocando los parámetros del ordenamiento neoliberal.

Es en este plano donde la asunción de un enfoque de derechos abre expectativas. Porque potencia el surgimiento de demandas, escenarios y sujetos que, más allá de avanzar en condiciones de inclusión en el campo de la protección social entendida como el doble movimiento de producción y reproducción del orden, aparezcan con mejores herramientas, a partir de la propia historicidad de los procesos de lucha implicados en estas redefiniciones semánticas, de mejores condiciones para poder pensar, también, alternativas de transformación social más globales.

\section{BIBLIOGRAFÍA}

Abramovich, V. (2006) "Una aproximación al enfoque de derechos en las estrategias y políticas de desarrollo". En Revista de la CEPAL N. ${ }^{\circ} 88$

Alonso, G. y Di Costa, V. (2011) "Cambios y continuidades en la política social argentina, 2003-2010". Ponencia preparada para su presentación en el VI Congreso Argentino de Administración Pública, a realizarse en la Ciudad de Resistencia, Chaco, el 6,7 y 8 de julio de 2011.

Andrenacci, L. (2002) "Algunas reflexiones en torno a la cuestión social y la asistencialización de la intervención social del Estado en la Argentina contemporánea". En Cuestión social, política social en el Gran Buenos Aires. Ediciones al Margen, Buenos Aires. 
Andrenacci, L. y Reppetto F. (2005). "Ciudadanía y política pública: dilemas de reconstrucción de la política social argentina". En Andrenacci, L. (compilador) Problemas de política social en la Argentina contemporánea. Prometeo Editorial. Bs. As.

Arceo, Nicolás, Mariana González, Nuria Mendizábal y Eduardo Basualdo (2010) "La crisis mundial y su impacto en América Latina", en La economía argentina de la postconvertibilidad en tiempos de crisis mundial. Editorial Cara o Ceca, Buenos Aires.

Belmartino, S.; Levin, S.; Reppeto, F. (2001) Políticas sociales y derechos sociales en la Argentina: breve historia de un retroceso. En Socialis. Reflexiones latinoamericanas sobre política social. Homo Sapiens, Vol. 5.

Boaventura de Sousa Santos (2010) "Refundación del Estado en América Latina. Perspectivas desde una epistemología del Sur". Perú.

Borghini, N.; Bressano, C.; Logiudice, A. (2012) "La actualidad de la política social. ¿Retorno del estado que no fue o nueva matriz de la asistencia?". Publicado en La Revista del CCC N. ${ }^{\circ} 16$ Año 6. ISSN 1851-3263

Bourdieu, P. (1999) "La Mano izquierda y la mano derecha del Estado". En Contrafuegos. Reflexiones para servir a la resistencia contra la invasión neoliberal. Editorial Anagrama, Barcelona.

Castel, R. (1997) "La metamorfosis de la cuestión social. Una crónica del salariado". Editorial Paidós, Buenos Aires

Cortés, M. (2009) "Estado y Movimientos Sociales en la Argentina: entre la autonomía y la institucionalidad". Ponencia presentada en el Congreso de la Asociación de Estudios Latinoamericanos, Río de Janeiro, Brasil, del 11 al 14 de junio de 2009.

Danani, C. y Grassi, E. (2008) "Ni error, ni omisión. El papel de la política de Estado en la producción de las condiciones de vida y de trabajo. El caso del sistema previsional en la Argentina (1993-2008)" En Lindemboim, J., Comp. Trabajo, ingresos y políticas en Argentina. Contribuciones para pensar el siglo XXI. Ed. Eudeba.

Danani, C. (2009) "La gestión de la política social: un intento de aportar a su problematización" En Chiara, M. y Di Virgilio, M. (org) Gestión de la política social: Conceptos y herramientas. UNGS/Editorial Prometeo. ISBN: 978-987-574-308-3.

Danani C. y Beccaria, A. (2011) "La (contra)reforma previsional argentina. 2004-2008: aspectos institucionales y políticos-culturales del proceso de transformación de la protección. En Danani, Hintze, S. (2011) (coord) Protecciones y desprotecciones. La seguridad social en la Argentina 1990-2010. Universidad Nacional de General Sarmiento. Argentina.

Danani, C. (2012) "Procesos de reformas y configuraciones de un nuevo régimen de política social: El trabajo, la seguridad social y los planes sociales en Argentina". Publicado en Revista Ciencias Sociales 135-136, No. Especial: 59-72 / 2012 (I-II)

De Sena, A (2011). "Promoción de microemprendimientos y políticas sociales: ¿Universalidad, Focalización o Masividad? Una discusión no acabada" En Pensamiento 
Plural, publicación del Instituto de Sociología e Política Mestrado em Ciencias Sociais, Universidade Federal de Pelotas. N. 1 (2011) pp. 36-67

Esping-Andersen, G. (1993) "Los tres mundos del Estado de Bienestar". Edicions Alfons El Magnanim. Institució Valenciana d’Estudis I Investigació. Generalitat Valenciana. Diputació Provincial de Valéncia.

García Linera, A.; Prada, R.; Tapia, L.; Vega Camacho, O. (2010) "El Estado como campo de lucha!" Muela del Diablo Editores. Bolivia.

Grassi, E. (2008) "La política social, las necesidades sociales y el principio de la igualdad: reflexiones para un debate 'psot-neoliberal'." En Ponce Jarrín, J. es posible pensar una nueva política social para América Latina. Flacso, Ecuador

Etchemendy, S. y Collier, R. (2007) "Golpeados pero de Pie: Resurgimiento Sindical y Neo-corporativismo Segmentado en Argentina (2003-2007)" Publicado en Politics and Society.

Merklen, D. (2005) "Pobres ciudadanos. Las clases populares en la era democrática (Argentina 1983-2003)" Editorial Gorla, Buenos Aires.

Palomino, H. (2010) "La instalación de un nuevo régimen de empleo en Argentina: de la precarización a la regulación" En: H. Palomino (ed.), La nueva dinámica de las relaciones laborales en la Argentina, Buenos Aires, Jorge Baudino Ediciones.

Retamozo, M. y Muñoz A. (2008) "Hegemonía y discurso en la Argentina contemporánea. Efectos políticos de los usos de 'pueblo' en la retórica de Néstor Kirchner". Perfiles Latinoamericanos.

Pautassi, L. (organizadora) (2010) "Perspectiva de derechos, políticas públicas e inclusión social. Debates actuales en Argentina". Editorial Biblos, Buenos Aires.

Pautassi, L. (2009) "El bicentenario de la política social. ¿Nuevos modelos o viejas estrategias?" Publicado en Postdata. ISSN 1515-209X (pp. 185-203).

Repetto, F. (2010) "Protección social en América Latina: la búsqueda de una integralidad con enfoque de derechos" Publicado en la Revista del CLAD Reforma y Democracia. No. 47. (Jun. 2010). Caracas.

Repetto, F. y Dalmasetto, F. (2011) "Protección Social en la Argentina" Publicación del Seminario: Diálogos de protección social. La protección social en argentina en perspectiva latinoamericana: retos de inclusión e integralidad, organizado por CIPPEC, CEPAL, Fundación Tzedaká y Universidad de San Andrés.

Santarsiero, L. (2012) "Las políticas sociales en el caso de la satisfacción de necesidades alimentarias. Algunos elementos conceptuales para su determinación." Publicado en Trabajo y Sociedad. Núcleo Básico de Revistas Científicas Argentinas (Caicyt- Conicet) N. ${ }^{\circ} 18$, vol XV. Santiago del Estero, Argentina.

Stefanoni, P. (2011) "Estado de la democracia en Venezuela, Bolivia y Ecuador." En OSAL Observatorio Social de América Latina Año XII N. ${ }^{\circ} 30$ / publicación semestral / Noviembre de 2011 pp. 79-111. Bs. As. 
Soldano D. y Andrenacci, L. (2006) "Aproximaciones a las teorías de la política social a partir del caso Argentino" en Andrenacci, L. Problemas de política social en la Argentina contemporánea. Prometeo Editorial, Buenos Aires.

Soldano, D. (2007) "Políticas sociales y desigualdad "después" del neoliberalismo. Un aporte teórico-metodológico." Ponencia presentada en $8 .^{\circ}$ Congreso Nacional de Sociología Jurídica "derecho, democracia y sociedad", 22, 23 y 24 de noviembre. Santa Fe, Argentina.

Thwaites Rey, M. (2010) "Después de la globalización neoliberal: ¿Qué Estado en América Latina?" en OSAL (Buenos Aires: CLACSO) Año XI, N. ${ }^{\circ} 27$, abril.

Villanueva, Ernesto (2008) "Una mirada a los recientes cambios en el Estado argentino. ¿Emergencia de un nuevo modelo?". Publicado en Espacio Abierto, Vol. 17, Núm. 4, octubre-diciembre, 2008, pp. 657-681 Asociación Venezolana de Sociología Venezuela. 